\title{
Treatment and prognostic factors for survival in newly diagnosed multiple myeloma patients with bortezomib and dexamethasone regimen: a single Chinese center retrospective study
}

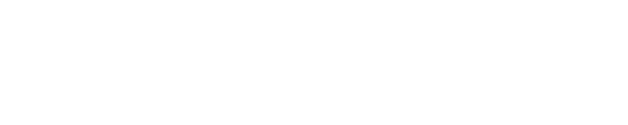

\section{Runzhe Chen \\ Xiaoping Zhang \\ Chong Gao \\ Chengxin Luan \\ Yujie Wang \\ Baoan Chen}

Department of Hematology and Oncology, Zhongda Hospital, Medical School, Southeast University, Nanjing, People's Republic of China
Correspondence: Baoan Chen Department of Hematology and Oncology, Zhongda Hospital, Medical School, Southeast University, Dingjiaqiao 87, Gulou District, Nanjing 210009 , Jiangsu Province, People's Republic of China

Tel +862583272006

Fax +86258327 20I I

Email cba8888@hotmail.com
Objective: The aim of this retrospective study was to evaluate the efficacy and prognostic factors of bortezomib and dexamethasone (BD) chemotherapy regimen in the treatment of newly diagnosed multiple myeloma (MM) patients in our hospital.

Methods: A total of 47 newly diagnosed MM patients treated in our hospital from May 2010 to September 2016 were included in this study. All the enrolled patients received at least two cycles of BD chemotherapy regimen.

Results: The overall response rate after treatment was $68.5 \%$ with a complete response of $23.4 \%$, very good partial response of $17.0 \%$, partial response of $21.3 \%$ and minor response of $6.8 \%$. The median time of overall survival (OS), progression-free survival (PFS) and time to progression (TTP) of the treated patients were 36.0, 19.0 and 18.0 months, respectively; the mean OS, PFS and TTP were 36.0, 19.3 and 18.8 months, respectively. Though some adverse events had occurred, none of the patients was discontinued from treatment. Level of albumin, $\beta_{2}$-microglobulin and cytogenetic abnormalities were prognostic factors for OS, and plasma cell percentage in bone marrow, $\beta_{2}$-microglobulin and cytogenetic abnormalities were prognostic factors for PFS as revealed by log-rank test of univariate analysis; no prognostic factors for OS and PFS were detected by COX regression of multivariate analysis.

Conclusion: Our study demonstrated that BD regimen was effective and well tolerated in newly diagnosed MM patients, and prognostic factors for patients' survival include level of albumin, plasma cell percentage in bone marrow, $\beta_{2}$-microglobulin and cytogenetic abnormalities.

Keywords: multiple myeloma, bortezomib, treatment, efficacy, survival, prognostic factors

\section{Introduction}

Multiple myeloma (MM) is the second most common hematological malignancy and has a very high incidence especially in the elderly people. ${ }^{1}$ Disease symptoms of MM include skeletal destruction, bone marrow failure, normal immunoglobulin production suppression and insufficiency of renal function. ${ }^{2}$ Treatment regimens of MM are developing very rapidly in decades. ${ }^{3-6}$ From the year 2000, a revolution for MM therapy has begun as a result of the emergence of new agents such as lenalidomide and bortezomib. ${ }^{7-9}$

For significantly improved clinical response in MM patients in clinical trials, bortezomib was approved by the US Food and Drug Administration (FDA) in 2003, and it has become the first-line therapy for MM since then. ${ }^{10,11}$ The ubiquitin-proteasome pathway can be blocked by selectively and reversibly inhibiting the activity 
of proteolysis of the proteasome complex, thus exerting an effect on anti-myeloma. ${ }^{2}$ Although overwhelming number of studies all over the world have investigated the role of bortezomib in MM in vivo and in vitro, very few studies from People's Republic of China have summarized the effect, tolerability and prognostic factors of bortezomib for newly diagnosed MM up to date. ${ }^{12-14}$ Although in recent years more new agents such as next generation of proteasome inhibitors (eg, carfilzomib) and immunomodulatory drugs (eg, pomalidomide) have been used in clinical trials and approved by the FDA, ${ }^{6,15,16}$ they are currently not available in the Chinese market. As a result, chemotherapy regimens including bortezomib are still the standardized treatment for MM in People's Republic of China. In order to better understand the role and effect of bortezomib in myeloma, summarizing and analyzing the prognostic factors in newly diagnosed MM patients treated by bortezomib is warranted.

\section{Methods}

Forty-seven newly diagnosed MM patients treated in Zhongda Hospital of Southeast University, People's Republic of China from May 2010 to September 2016 were enrolled in this study. All the patients had received at least two cycles of bortezomib and dexamethasone (BD) regimen. The diagnosis was evaluated and confirmed by the International Myeloma Working Group (IMWG) criteria. ${ }^{17,18}$

This study was waived from the requirement of obtaining patient informed consent because the patients remained anonymous in the study. All aspects of the study conformed to the Declaration of Helsinki. This study was approved by the Institutional Review Board of Zhongda Hospital of Southeast University (2016ZDSYLL018.1).

The included patients were treated with the following regimen: bortezomib $\left(1.3 \mathrm{mg} / \mathrm{m}^{2}\right.$ subcutaneously or intravenously on days $1,4,8$ and 11 of the 21 -day cycle or 1.3 $\mathrm{mg} / \mathrm{m}^{2}$ subcutaneously or intravenously on days $1,8,15$ and 22 of every 35 -day cycle) combined with dexamethasone 8 or $16 \mathrm{mg}$ was given to patients on the day of or 1 day after bortezomib therapy. If grade 3 or 4 hematological toxicities occurred in patients, the next chemotherapy would be postponed until the recovery of blood cells and dosage of bortezomib also be reduced in subsequent cycles. Granulocyte colony-stimulating factor would be given to the needed patients to boost the counts of white blood cells (WBC) less than $0.5 \times 10^{9} / \mathrm{L}$. For the included patients who were eligible for hematopoietic stem cell transplantation (SCT), 5 received autologous SCT and 1 was received allogeneic SCT.
Demographics of patients including age when diagnosed, sex, performance status, International Staging System (ISS) stage, Durie-Salmon (DS) stage, type of M proteins, classification of bone destruction, plasma cell percentage in bone marrow, level of hemoglobin and platelet, serum calcium, alanine aminotransferase, aspartate aminotransferase, lactate dehydrogenase, blood urea nitrogen, creatinine, C-reaction protein, $\beta_{2}$-microglobulin, extramedullary disease, urine protein occurrence, number of patients who underwent SCT and cytogenetic abnormalities were collected. Overall survival (OS) was defined as the time from the first administration of $\mathrm{BD}$ regimen to patient death, progression-free survival (PFS) was calculated as the time from the initial administration of BD regimen to the identification date of progressive disease (PD) or death and time to progression (TTP) was calculated as the time from the first administration of BD regimen to progression of disease or to the initiation of other therapy. Responses of patients were evaluated according to the IMWG uniform response criteria: complete response (CR) was defined by the absence of $\mathrm{M}$ protein in serum and urine and confirmed by the disappearance of soft tissue plasmacytomas and presence of $<5 \%$ bone marrow plasma cells; very good partial response (VGPR) met all of the criteria for partial response (PR) and also $\mathrm{M}$ proteins were detected by immunofixation but not on electrophoresis or serum $\mathrm{M}$ protein reduction $\geq 90 \%$ and urine $\mathrm{M}$ protein $<100 \mathrm{mg} / 24 \mathrm{~h}$; PR was defined by at least a $50 \%$ reduction of serum $\mathrm{M}$ proteins and urine $\mathrm{M}$ protein $<200 \mathrm{mg} / 24 \mathrm{~h}$; minor response (MR) was defined by $\geq 25 \%$ but $<49 \%$ reduction of serum $M$ protein and reduction of $24-\mathrm{h}$ urine M protein by $50 \%-89 \%$ but still exceeded $200 \mathrm{mg} / 24 \mathrm{~h}$ and $\mathrm{PD}$ was called when $\mathrm{M}$ protein was $>25 \%$ or increased in serum or urine, or increased bone marrow plasma cells, bone lesions or plasmacytomas, or new hypercalcemia occurred. Adverse events were evaluated according to National Cancer Institute Common Terminology Criteria for Adverse Events version 4.0. ${ }^{19,20}$ OS, PFS and TTP were analyzed by KaplanMeier method. Log-rank test was used to identify the univariate prognostic factors independently associated with OS and PFS, and Cox regression was applied to identify the multivariate prognostic factors independently associated with OS and PFS. All statistical analyses were performed by SPSS version 22.0 statistical software (Chicago, IL, USA). The value of $p$ less than 0.05 was considered statistically significant.

\section{Results}

\section{Patient characteristics}

The clinical characteristics of the included 47 patients before the BD regimen therapy are shown in Table 1. Disease 
Table I Clinical characteristic of the included MM patients

\begin{tabular}{|c|c|}
\hline Characteristics & Patients, \% \\
\hline Total number of patients & 47 \\
\hline Age (years), median (range) & $65(4 \mid-86)$ \\
\hline \multicolumn{2}{|l|}{ Sex, n (\%) } \\
\hline Female & $21(44.7)$ \\
\hline Male & $26(55.3)$ \\
\hline \multicolumn{2}{|l|}{ Performance status, n (\%) } \\
\hline 0 & $6(12.8)$ \\
\hline I & $23(48.9)$ \\
\hline 2 & II (23.4) \\
\hline$\geq 3$ & $7(14.9)$ \\
\hline \multicolumn{2}{|l|}{ ISS stage, n (\%) } \\
\hline I & II (23.4) \\
\hline II & $12(25.5)$ \\
\hline III & $24(51.1)$ \\
\hline \multicolumn{2}{|l|}{ DS stage, $n(\%)$} \\
\hline IA & $0(0)$ \\
\hline IB & $I(2.1)$ \\
\hline IIA & $13(27.7)$ \\
\hline IIB & $2(4.3)$ \\
\hline IIIA & $21(44.7)$ \\
\hline IIIB & $10(21.3)$ \\
\hline \multicolumn{2}{|l|}{ Type of M proteins, $n$ (\%) } \\
\hline $\lg G$ & $24(51.1)$ \\
\hline $\lg A$ & $9(19.1)$ \\
\hline $\lg D$ & $2(4.3)$ \\
\hline $\lg M$ & $2(4.3)$ \\
\hline Light chain & $7(14.9)$ \\
\hline Not secreted & $3(6.4)$ \\
\hline \multicolumn{2}{|l|}{ Bone destruction, n (\%) } \\
\hline $0-1$ & II (23.4) \\
\hline 2 & $22(46.8)$ \\
\hline$\geq 3$ & $14(29.8)$ \\
\hline Percentage of plasma cells in bone marrow, \% & $34.6(1.6-75.6)$ \\
\hline $\mathrm{Hb}, \mathrm{g} / \mathrm{L}$ & $98(57-144)$ \\
\hline $\mathrm{PLT}, \times 10^{9} / \mathrm{L}$ & I5I (56-555) \\
\hline Alb, g/L & $31(19-46)$ \\
\hline Calcium, $\mathrm{mmol} / \mathrm{L}$ & $2.21(1.58-3.66)$ \\
\hline ALT, IU/L & $21(8-108)$ \\
\hline AST, IU/L & $28(11-73)$ \\
\hline LDH, IU/L & $183(34-35 \mid)$ \\
\hline Creatinine, $\mu \mathrm{mol} / \mathrm{L}$ & $109(4 I-1254)$ \\
\hline $\mathrm{BUN}, \mathrm{mmol} / \mathrm{L}$ & $5.17(1.26-74.20)$ \\
\hline CRP, mg/L & $8.3(2.2-4 I)$ \\
\hline$\beta_{2}-$ Microglobulin, mg/L & $1.17(0.2-14.1)$ \\
\hline Extramedullary disease, $\mathrm{n}(\%)$ & $14(47)$ \\
\hline Urine protein, n (\%) & $21(36)$ \\
\hline No. of SCT & 6 \\
\hline Auto-SCT, n (\%) & $5(83.3)$ \\
\hline Allo-SCT, n (\%) & I (16.7) \\
\hline Cytogenetic abnormalities, n (\%) & $3 / 19(15.8)$ \\
\hline Deletion of chromosome 13 & 2 \\
\hline Deletion of chromosome 17 & 0 \\
\hline $\mathrm{t}(\mathrm{II} ; \mid 4)$ & 1 \\
\hline $\mathrm{t}(4 ; 14)$ & 0 \\
\hline
\end{tabular}

Note: Data presented as median (range) unless indicated otherwise.

Abbreviations: Alb, albumin; Allo, allogeneic; ALT, alanine aminotransferase; AST, aspartate aminotransferase; Auto, autologous; BUN, blood urea nitrogen; CRP, C-reaction protein; DS, Durie-Salmon; Hb, hemoglobin; Ig, immunoglobulin; ISS, International Staging System; LDH, lactate dehydrogenase; MM, multiple myeloma; PLT, platelet; SCT, stem cell transplantation. stages were confirmed by DS classification and ISS. The median age of MM patients was 65 (41-86) years. MM subtype of most patients (70.2\%) were IgG and IgA. Six patients received SCT. Among the 19 patients who underwent chromosome testing, 3 were found to have cytogenetic abnormalities.

\section{Response to therapy}

Responses to BD regimen are demonstrated in Table 2. Overall response was seen in $68.5 \%$ patients: $\mathrm{CR}$ was achieved in 11 patients $(23.4 \%)$, VGPR was achieved in 8 patients (17.0\%), PR was achieved in 10 patients $(21.3 \%)$ and $M R$ was seen in 3 patients $(6.8 \%)$.

\section{Safety}

Adverse events of the treatment are listed in Table 3. The most common toxic effects occurring during treatment were neutropenia and peripheral neuropathy. Other commonly reported toxic effects were anemia, thrombocytopenia, infection, diarrhea, vomiting, deep venous thrombosis and fatigue. None of the patients were discontinued from treatment because of adverse events.

Table 2 Response in the MM patients after treatment

\begin{tabular}{ll}
\hline Response & Patients, $\mathbf{n}(\%)$ \\
\hline CR & $11(23.4)$ \\
VGPR & $8(17.0)$ \\
CR + VGPR (high quality response) & $19(40.4)$ \\
PR & $10(21.3)$ \\
MR & $3(6.8)$ \\
SD & $5(10.6)$ \\
PD & $10(21.3)$ \\
\hline
\end{tabular}

Abbreviations: $C R$, complete response; MM, multiple myeloma; $M R$, minor response; PD, progressive disease; PR, partial response; SD, stable disease; VGPR, very good partial response.

Table 3 Major adverse events of MM patients

\begin{tabular}{ll}
\hline Adverse events & Patients $(\mathbf{n = 4 7 )}$ \\
\hline Hematological & \\
Neutropenia $\geq$ grade 3 & $18(38.3)$ \\
Anemia $\geq$ grade 2 & $12(25.5)$ \\
Thrombocytopenia $\geq$ grade 3 & $3(6.4)$ \\
Infective $\geq$ grade I & \\
Fever of unknown origin & $5(10.6)$ \\
Herpes zoster & $4(8.5)$ \\
Upper respiratory tract infection & $8(17.0)$ \\
Peripheral neuropathy $\geq$ grade 3 & $14(29.8)$ \\
Constipation & $12(25.5)$ \\
Diarrhea & $7(14.9)$ \\
Vomiting & $6(12.8)$ \\
Deep venous thrombosis & $3(6.4)$ \\
Fatigue $\geq$ grade 2 & $11(23.4)$ \\
\hline Note: Dat presed
\end{tabular}

Note: Data presented as $\mathrm{n}(\%)$.

Abbreviation: MM, multiple myeloma. 


\section{Survival and prognostic factors}

The median OS, PFS and TTP of these MM patients were 36.0 months (95\% confidence interval [CI]: 32.8-39.2 months), 19.0 months (95\% CI: $15.7-22.3$ months) and 18.0 months (95\% CI: 14.4-21.6 months), respectively; the mean OS, PFS and TTP were 36.0 months (95\% CI: 31.8-40.3), 19.3 months (95\% CI: 16.6-22.0) and 18.8 months (95\% CI: 16.2-21.3), respectively (Figures 1-3).

Associations between patient characteristics and OS and PFS were also evaluated. In the present study, logrank test indicated that level of albumin, $\beta_{2}$-microglobulin and cytogenetic abnormalities were prognostic factors for OS; high level of albumin as well as $\beta_{2}$-microglobulin and cytogenetic abnormalities was associated with poor OS (Table 4, Figure 4). Plasma cell percentage in bone marrow, $\beta_{2}$-microglobulin and cytogenetic abnormalities were prognostic factors for PFS; high percentage of plasma cells in bone marrow, high $\beta_{2}$-microglobulin and cytogenetic abnormalities were associated with poor PFS (Table 5, Figure 5). No prognostic factors for OS and PFS were revealed by COX regression of multivariate analysis.

\section{Discussion}

$\mathrm{MM}$ is a plasma disorder that accounts for approximately $10 \%$ of all hematologic malignancies. ${ }^{21}$ It is considered as an incurable disease with a median survival of about 3 to 4 years if treated by conventional regimen. ${ }^{21,22}$ Multiple factors play roles in determining the best course of therapy and so the treatment of MM is quite individualized. ${ }^{23} \mathrm{BD}$ regimen is currently the standard chemotherapy regimen for MM patients in People's Republic of China. For the included 47 newly diagnosed MM patients in our study, median time of OS, PFS and TTP were 36.0, 19.0 and 18.0 months, respectively, which were similar to the studies reported previously. ${ }^{12,17}$ For safety and tolerability, our results indicated that neutropenia and peripheral neuropathy were the two most common side effects caused by BD regimen. No patient was stopped from treatment because of those side effects, and this also proved that $\mathrm{BD}$ regimen was relatively safe and well tolerated..$^{24-27}$

In this study, level of albumin, $\beta_{2}$-microglobulin and cytogenetic abnormalities were prognostic factors for OS; plasma cell percentages in bone marrow, $\beta_{2}$-microglobulin and cytogenetic abnormalities were prognostic factors for PFS. It was indicated in our study that prognosis of patients with higher levels of albumin, $\beta_{2}$-microglobulin and plasma cell percentage in bone marrow may be worse than those patients with lower levels of these parameters. For the published studies analyzing prognostic factors of survival of Chinese MM patients, our results were not so consistent with them. ${ }^{12-14,17}$ In the study by Lu et al, ${ }^{12}$ sex, ISS stage, number of FISH abnormalities and extramedullary disease were the prognostic factors for survival, and no prognostic factors were observed by Guo et al. ${ }^{14}$ More

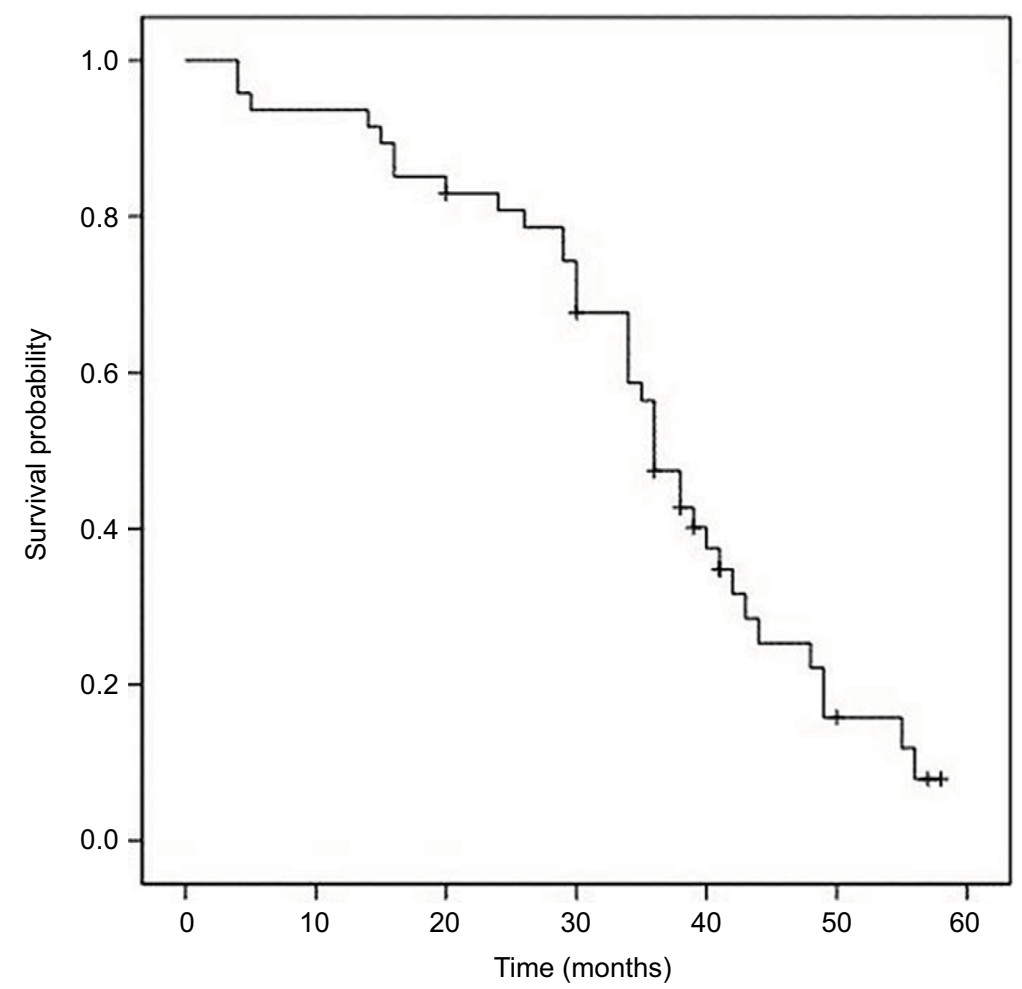

Figure I Overall survival curve in the treated multiple myeloma patients. 


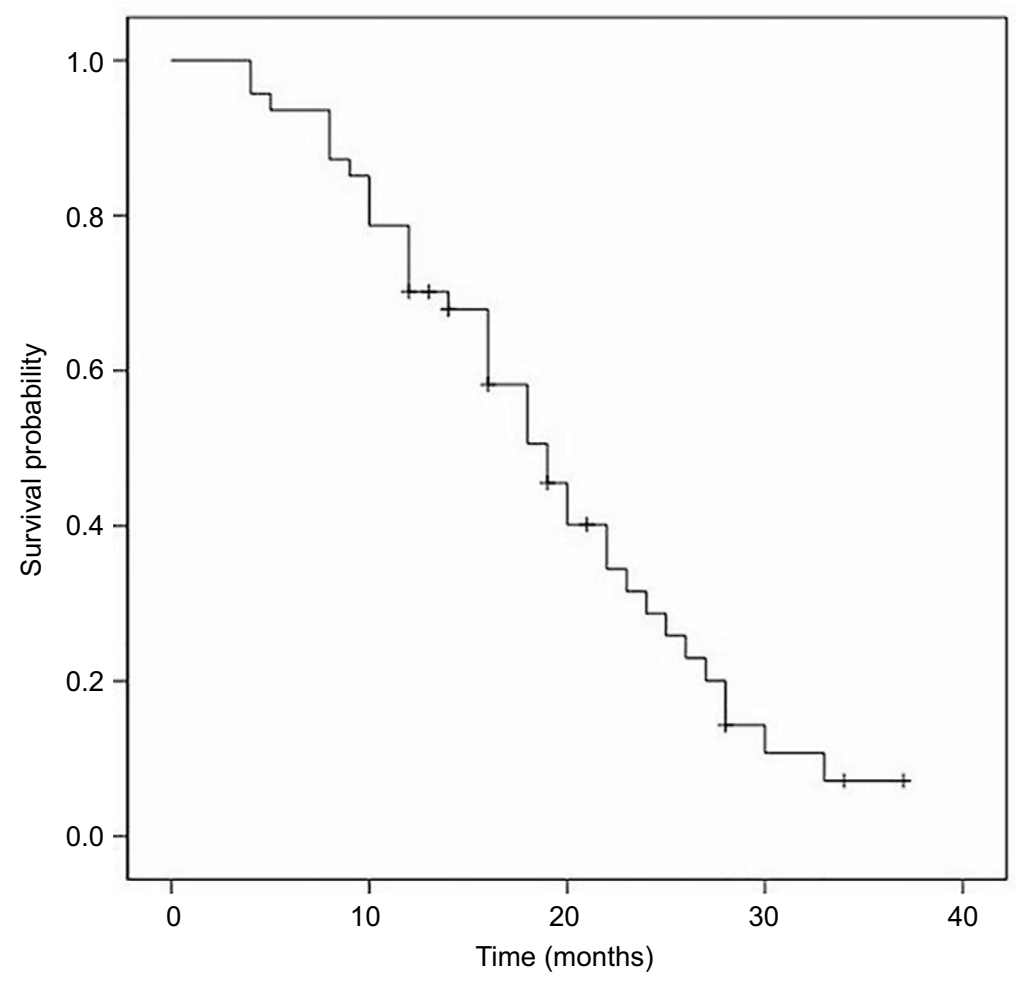

Figure 2 Progression-free survival curve in the treated multiple myeloma patients.

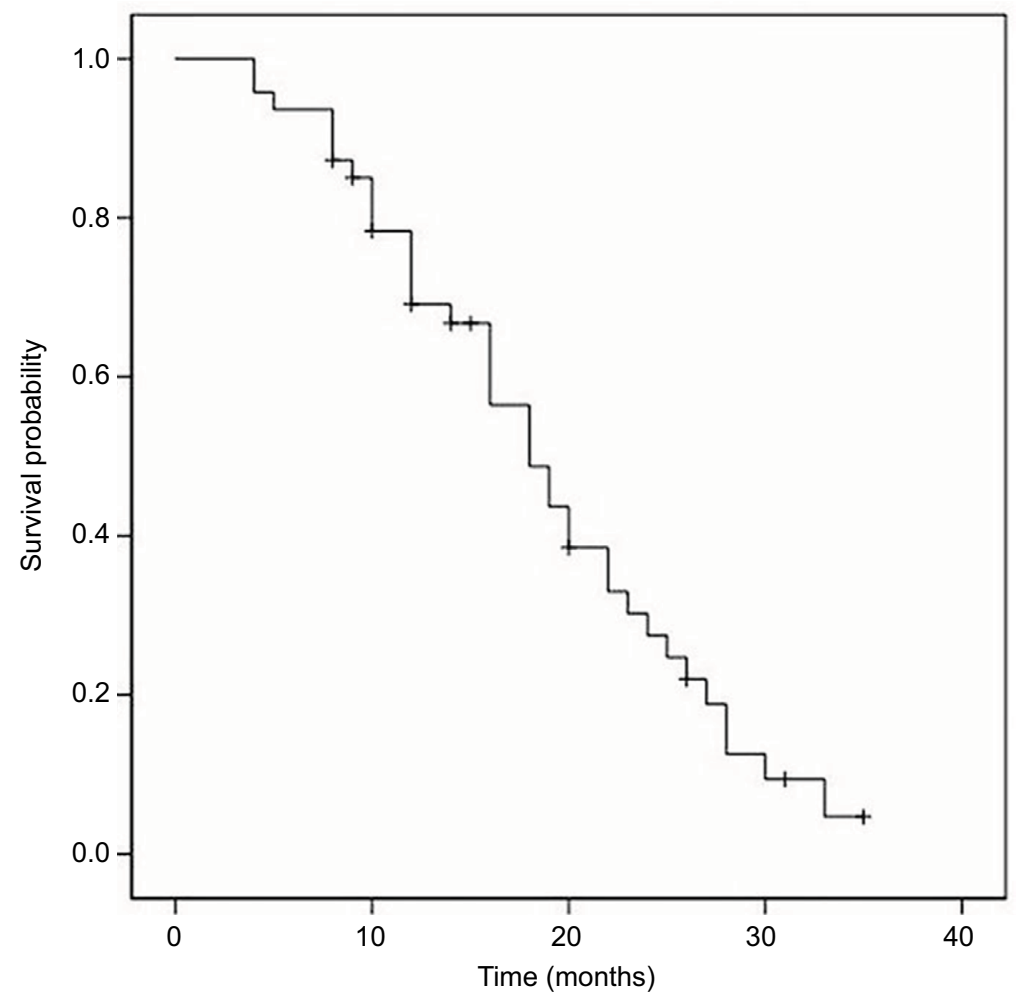

Figure 3 Time to progression curve in the treated multiple myeloma patients.

interestingly, theoretically high levels of albumin should be correlated with better outcome, but opposite results were found in this study. The potential explanation for the discrepancies might be because of the different groups of patients and centers in People's Republic of China. Inadequate cytogenetic data, small sample size and heterogeneity of MM patients are also the reasons. We believe that with more standard treatment strategies as well as higher qualified and multicenter studies 
Table 4 Prognostic factors for OS

\begin{tabular}{|c|c|c|c|c|c|c|}
\hline \multirow[t]{2}{*}{ Prognostic factors } & \multirow[t]{2}{*}{ Total number } & \multicolumn{5}{|l|}{ OS } \\
\hline & & $\begin{array}{l}\text { Mean (months), } \\
\text { mean } \pm \text { SD }\end{array}$ & $95 \% \mathrm{Cl}$ & $\begin{array}{l}\text { Median (months), } \\
\text { median } \pm \text { SD }\end{array}$ & $95 \% \mathrm{Cl}$ & $p$-value \\
\hline Alb, g/L & 47 & & & & & 0.046 \\
\hline$<35$ & 35 & $38.8 \pm 2.1$ & $34.6-42.9$ & $38.0 \pm 2.0$ & $34.0-42.0$ & \\
\hline$\geq 35$ & 12 & $25.8 \pm 3.9$ & $18.1-33.4$ & $29.0 \pm 7.6$ & $14.1-43.9$ & \\
\hline$\beta_{2}$-Microglobulin, $\mathrm{mg} / \mathrm{L}$ & 47 & & & & & 0.003 \\
\hline$<3.5$ & 41 & $37.9 \pm 2.2$ & $33.5-42.3$ & $38.0 \pm 2.1$ & $33.9-42.1$ & \\
\hline$\geq 3.5$ & 6 & $23.7 \pm 5.1$ & 13.6-33.7 & $20.0 \pm 9.2$ & $2.0-38.0$ & \\
\hline Cytogenetic abnormalities & 19 & & & & & 0.000 \\
\hline Yes & 3 & $20.0 \pm 0.0$ & $20.0-20.0$ & $20.0 \pm 0.0$ & & \\
\hline No & 16 & $53.5 \pm 2.3$ & $48.9-58.1$ & & & \\
\hline
\end{tabular}

Abbreviations: Alb, albumin; $\mathrm{Cl}$, confidence interval; OS, overall survival.

A

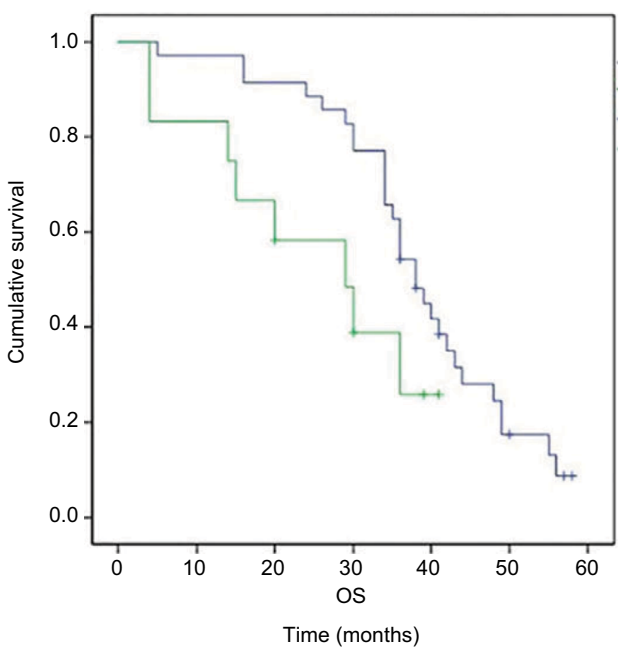

$-<35 \mathrm{~g} / \mathrm{L}$
$-\geq 35 \mathrm{~g} / \mathrm{L}$
$+<35 \mathrm{~g} / \mathrm{L}$-censored
$+-\geq 35 \mathrm{~g} / \mathrm{L}-$-censored

C

Survival functions
B Survival functions

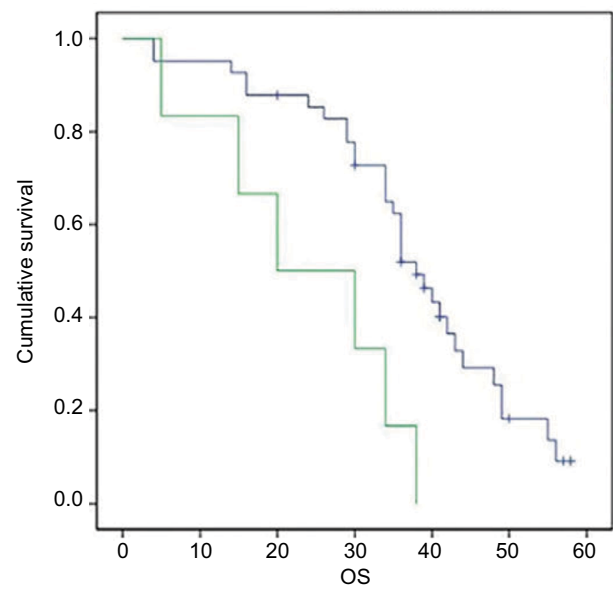

Time (months)

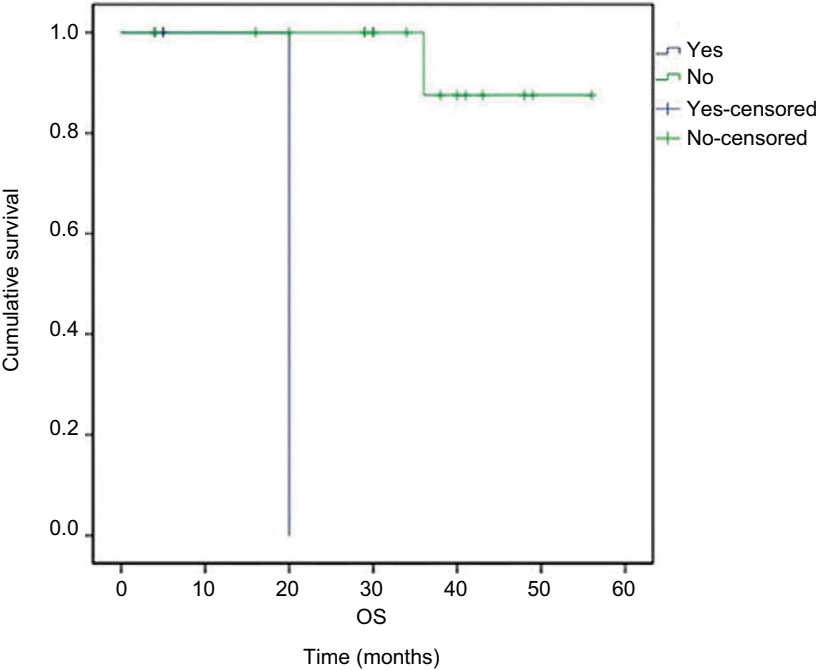

Figure 4 Impact of $(\mathbf{A})$ albumin, (B) $\beta_{2}$-microglobulin and (C) cytogenetic abnormalities in overall survival (OS) of the treated multiple myeloma patients. 
Table 5 Prognostic factors for PFS

\begin{tabular}{|c|c|c|c|c|c|c|}
\hline \multirow[t]{2}{*}{ Prognostic factors } & \multirow[t]{2}{*}{ Total number } & \multicolumn{5}{|l|}{ PFS } \\
\hline & & $\begin{array}{l}\text { Mean (months), } \\
\text { mean } \pm \text { SD }\end{array}$ & $95 \% \mathrm{Cl}$ & $\begin{array}{l}\text { Median (months), } \\
\text { median } \pm \text { SD }\end{array}$ & $95 \% \mathrm{Cl}$ & p-value \\
\hline Percentage of plasma cells in bone marrow, $\%$ & 47 & & & & & 0.033 \\
\hline$<30$ & 27 & $21.7 \pm 1.8$ & $18.2-25.2$ & $22.0 \pm 3.8$ & | $4.6-29.4$ & \\
\hline$\geq 30$ & 20 & $16.3 \pm 1.7$ & $12.8-19.7$ & $16.0 \pm 2.2$ & II.6-20.4 & \\
\hline$\beta_{2}$-Microglobulin, mg/L & 47 & $37.9 \pm 2.2$ & $33.5-42.3$ & $38.0 \pm 2.1$ & $33.9-42.1$ & 0.001 \\
\hline$<3.5$ & 41 & $20.5 \pm 1.5$ & I7.6-23.4 & $20.0 \pm 1.8$ & $16.5-23.5$ & \\
\hline$\geq 3.5$ & 6 & $11.3 \pm 1.7$ & $7.9-14.8$ & $12.0 \pm 0.9$ & $10.2-13.8$ & \\
\hline Cytogenetic abnormalities & 19 & & & & & 0.000 \\
\hline Yes & 3 & $12.0 \pm 0.0$ & $12.0-12.0$ & $12.0 \pm 0.0$ & & \\
\hline No & 16 & $29.0 \pm 0.7$ & $27.6-30.4$ & $28.0 \pm 0.0$ & & \\
\hline
\end{tabular}

Abbreviations: $\mathrm{Cl}$, confidence interval; PFS, progression-free survival.

A

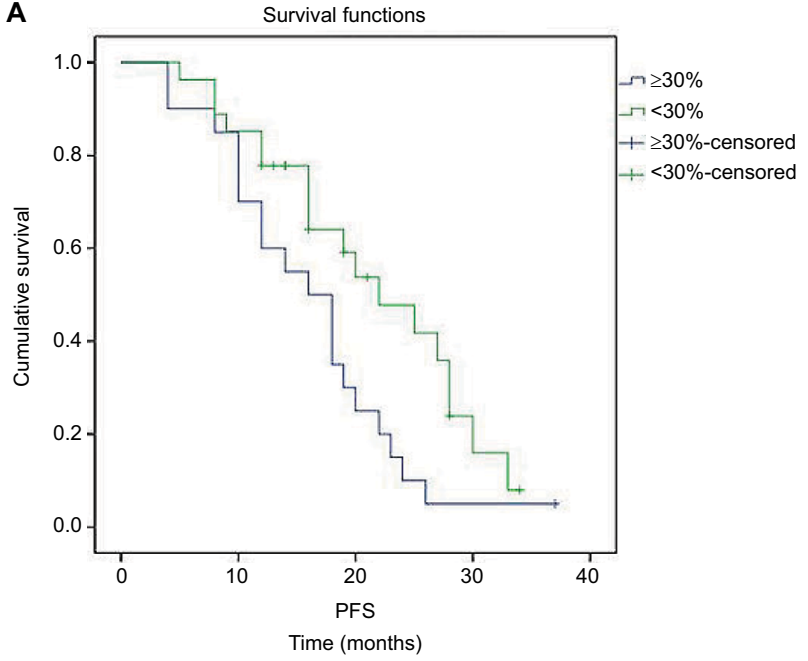

B

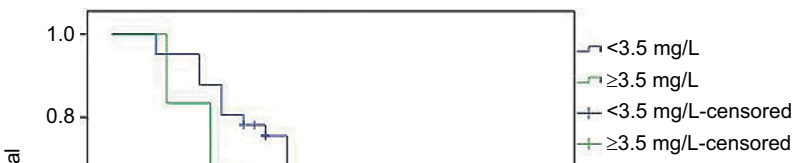

C

Survival functions

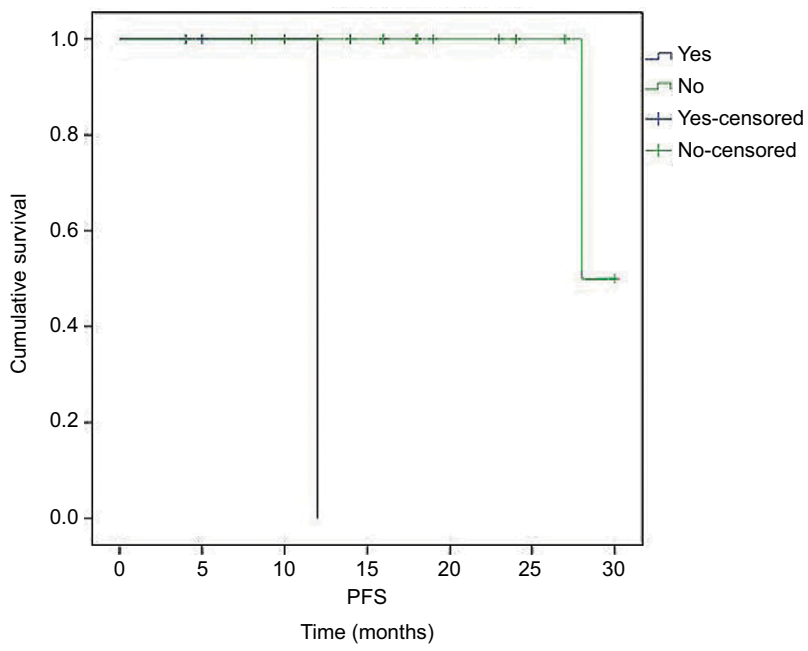

Figure 5 Impact of (A) percentage of plasma cells in bone marrow, (B) $\beta_{2}$-microglobulin and (C) cytogenetic abnormalities in progression-free survival of the treated multiple myeloma patients.

Abbreviation: PFS, progression-free survival. 
including more patient samples, the power of the study will certainly be increased. Approval of novel therapeutic agents in the Chinese market for MM and development of precise and effective treatment will also hopefully increase response in MM patients after chemotherapy.

\section{Acknowledgments}

This study was supported by National Natural and Science Foundation of People's Republic of China (81370673), Key Medical Project of Jiangsu Province (BL2014078) and Key Medical Discipline of Jiangsu Province (2016-2020).

\section{Disclosure}

The authors report no conflicts of interest in this work.

\section{References}

1. San Miguel JF. Introduction to a series of reviews on multiple myeloma. Blood. 2015;125(20):3039-3040.

2. Sonneveld P, Goldschmidt H, Rosiñol L, et al. Bortezomib-based versus nonbortezomib-based induction treatment before autologous stem-cell transplantation in patients with previously untreated multiple myeloma: a meta-analysis of phase III randomized, controlled trials. J Clin Oncol. 2013;31(26):3279-3287.

3. Palumbo A, Facon T, Sonneveld P, et al. Thalidomide for treatment of multiple myeloma: 10 years later. Blood. 2008;111(8):3968-3977.

4. Barlogie B, Epstein J, Selvanayagam P, Alexanian R. Plasma cell myeloma-new biological insights and advances in therapy. Blood. 1989;73(4):865-879.

5. Barlogie B, Shaughnessy J, Tricot G, et al. Treatment of multiple myeloma. Blood. 2004;103(1):20-32.

6. Chen R, Chen B, Zhang X, Gao C. Efficacy of carfilzomib in the treatment of relapsed and (or) refractory multiple myeloma: a meta-analysis of data from clinical trials. Discov Med. 2016;22(121):189-199.

7. Shaughnessy JD Jr, Qu P, Usmani S, et al. Pharmacogenomics of bortezomib test-dosing identifies hyperexpression of proteasome genes, especially PSMD4, as novel high-risk feature in myeloma treated with Total Therapy 3. Blood. 2011;118(13):3512-3524.

8. Driscoll J. Expression of E3 ubiquitin ligases in multiple myeloma patients after treatment with the proteasome inhibitor bortezomib. Cancer Transl Med. 2015;1(5):153-157.

9. Dai C, Chen D, Jiang Y. Histone H2A and H2B deubiquitinase in developmental disease and cancer. Cancer Transl Med. 2015;1(5):170-175.

10. Mohty M, Malard F, Mohty B, Savani B, Moreau P, Terpos E. The effects of bortezomib on bone disease in patients with multiple myeloma. Cancer. 2014;120(5):618-623.

11. Aguiar PM, de Mendonca Lima T, Colleoni GWB, Storpirtis S. Efficacy and safety of bortezomib, thalidomide, and lenalidomide in multiple myeloma: an overview of systematic reviews with meta-analyses. Crit Rev Oncol Hematol. 2017;113:195-212.
12. Lu J, Lu J, Chen W, HuoY, Huang X, Hou J. Clinical features and treatment outcome in newly diagnosed Chinese patients with multiple myeloma: results of a multicenter analysis. Blood Cancer J. 2014;4(8):e239.

13. Li F, Xu Y, Deng P, et al. Heterogeneous chromosome 12p deletion is an independent adverse prognostic factor and resistant to bortezomib-based therapy in multiple myeloma. Oncotarget. 2015;6(11): 9434-9444.

14. Guo H, Zhou X, Jiang Y, et al. Bortezomib plus intermediate-dose dexamethasone and thalidomide in elderly untreated patients with multiple myeloma: a Chinese experience. Am J Hematol. 2010;85(7): 499-501.

15. Chen R, Chen B, Ge Z. Efficacy of carfilzomib in the treatment of relapsed and (or) refractory multiple myeloma: a meta analysis of individual patient data from clinical trials. Blood. 2016;128(22):5675.

16. Chen R, Wang Y, Luan C, Gao C, Zhang X, Chen B. Effect of pomalidomide on relapsed/refractory multiple myeloma: a systematic review and meta-analysis. J Cancer. 2017;8(10):1801-1808.

17. Kiba T, Ito T, Nakashima T, et al. Bortezomib and dexamethasone for multiple myeloma: higher AST and LDH levels associated with a worse prognosis on overall survival. BMC Cancer. 2014;14:462.

18. Chen RA, Tu Y, Cao Y, Liu L, Liang Y. Bortezomib-dexamethasone or vincristine-doxorubicin-dexamethasone as induction therapy followed by thalidomide as maintenance therapy in untreated multiple myeloma patients. J Int Med Res. 2011;39(5):1975-1984.

19. Zeng W, Meng F, Liu Z, et al. Bortezomib-based chemotherapy regimens can improve response in newly diagnosed multiple myeloma patients with bcl-2 and survivin overexpression. Int J Clin Exp Pathol. 2014;7(7): 4239-4246.

20. Zwickl H, Zwickl-Traxler E, Pecherstorfer M. A single-center retrospective analysis of first-line therapy of multiple myeloma with bendamustine-bortezomib-dexamethasone. Leuk Lymphoma. 2016;57(9): 2065-2070.

21. Bianchi G, Anderson KC. Understanding biology to tackle the disease: multiple myeloma from bench to bedside, and back. CA Cancer J Clin. 2014;64(6):422-444.

22. Bianchi G, Munshi NC. Pathogenesis beyond the cancer clone(s) in multiple myeloma. Blood. 2015;125(20):3049-3058.

23. Cejalvo MJ, de la Rubia J. Clinical treatment of newly diagnosed multiple myeloma. Expert Rev Hematol. 2015;8(5):595-611.

24. Richardson PG, Sonneveld P, Schuster MW, et al; Assessment of Proteasome Inhibition for Extending Remissions (APEX) Investigators. Bortezomib or high-dose dexamethasone for relapsed multiple myeloma. N Engl J Med. 2005;352(24):2487-2498.

25. Harousseau JL, Attal M, Leleu X, et al. Bortezomib plus dexamethasone as induction treatment prior to autologous stem cell transplantation in patients with newly diagnosed multiple myeloma: results of an IFM phase II study. Haematologica. 2006;91(11):1498-1505.

26. Sonneveld P, Schmidt-Wolf IG, van der Holt B, et al. Bortezomib induction and maintenance treatment in patients with newly diagnosed multiple myeloma: results of the randomized phase III HOVON-65/ GMMG-HD4 trial. J Clin Oncol. 2012;30(24):2946-2955.

27. Liu X, He CK, Meng X, et al. Bortezomib-based vs non-bortezomibbased post-transplantation treatment in multiple myeloma patients: a systematic review and meta-analysis of Phase III randomized controlled trials. Onco Targets Ther. 2015;8:1459-1469.
Cancer Management and Research

\section{Publish your work in this journal}

Cancer Management and Research is an international, peer-reviewed open access journal focusing on cancer research and the optimal use of preventative and integrated treatment interventions to achieve improved outcomes, enhanced survival and quality of life for the cancer patient. The manuscript management system is completely online and includes

Submit your manuscript here: https://www.dovepress.com/cancer-management-and-research-journal 